\title{
Comparison of the clinicopathological features and oncologic outcomes of the classic papillary thyroid carcinoma with tall cell features and tall cell variant
}

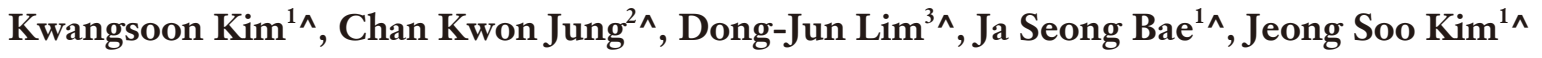 \\ ${ }^{1}$ Department of Surgery, College of Medicine, The Catholic University of Korea, Seoul, Korea; ${ }^{2}$ Department of Hospital Pathology, College of \\ Medicine, The Catholic University of Korea, Seoul, Korea; ${ }^{3}$ Division of Endocrinology and Metabolism, Department of Internal Medicine, College \\ of Medicine, The Catholic University of Korea, Seoul, Korea \\ Contributions: (I) Conception and design: JS Bae; (II) Administrative support: CK Jung, DJ Lim, JS Kim; (III) Provision of study materials or patients: \\ K Kim, JS Bae, JS Kim; (IV) Collection and assembly of data: K Kim, CK Jung, JS Bae; (V) Data analysis and interpretation: K Kim, JS Bae; (VI) \\ Manuscript writing: All authors; (VII) Final approval of manuscript: All authors. \\ Correspondence to: Ja Seong Bae, MD, PhD. Professor, Department of Surgery, College of Medicine, The Catholic University of Korea, 222, Banpo- \\ daero, Seocho-gu, 06591, Seoul, Korea. Email: Jaseong@gmail.com.
}

\begin{abstract}
Background: The tall cell variant (TCV) of papillary thyroid carcinoma (PTC) (TCVPTC) is the most common aggressive variant of PTC. Classic PTC with tall cell features (TCF) is defined as PTC with noticeable tall cells but the percentage of these cells is lower than that required for the diagnosis of TCVPTC. We aimed to investigate the potential differences between TCVPTC and classic PTC with TCF with respect to clinicopathological characteristics and oncologic outcomes.

Methods: We retrospectively assessed 509 patients with TCVPTC or classic PTC with TCF who underwent thyroid surgery between January 2013 and December 2018 at the Seoul St. Mary's Hospital (Seoul, Korea). Clinicopathological characteristics and oncologic outcomes between TCVPTC and classic PTC with TCF were compared in terms of disease-free survival (DFS). The mean follow-up duration was $70.7 \pm 21.7$ months.

Results: The mean tumor size was significantly larger in the TCVPTC group. There was no significant difference between the TCVPTC and classic PTC with TCF groups with respect to DFS. Tumor size $>2 \mathrm{~cm}$ [odds ratio (OR), 1.922; $\mathrm{P}=0.019$ ], bilaterality $(\mathrm{OR}, 1.668 ; \mathrm{P}=0.030)$, extrathyroidal extension (ETE) (OR, 2.352; $\mathrm{P}=0.002)$, and lateral $\mathrm{LN}$ metastasis $(\mathrm{OR}, 1.700 ; \mathrm{P}=0.045)$ were significantly associated with TCVPTC compared with classic PTC with TCF.

Conclusions: TCVPTC and classic PTC with TCF have similar clinicopathological characteristics and oncologic outcomes. Therefore, we suggest a potential re-classification of classic PTC with TCF from lowrisk to intermediate-risk category in the American Thyroid Association (ATA) risk stratification system.
\end{abstract}

Keywords: Tall cell features (TCF); tall cell variant (TCV); papillary thyroid carcinoma (PTC); disease-free survival (DFS)

Submitted Sep 30, 2021. Accepted for publication Dec 15, 2021.

doi: 10.21037 /gs-21-678

View this article at: https://dx.doi.org/10.21037/gs-21-678

\footnotetext{
^ ORCID: Kwangsoon Kim, 0000-0001-6403-6035; Chan Kwon Jung, 0000-0001-6843-3708; Dong-Jun Lim, 0000-0003-0995-6482; Ja Seong Bae, 0000-0002-6271-2105; Jeong Soo Kim, 0000-0002-9982-7838.
} 


\section{Introduction}

Papillary thyroid carcinoma (PTC) is the most common subtype of thyroid cancer accounting for $>85 \%$ of all thyroid cancers $(1,2)$. PTC is typically indolent, with excellent overall prognosis and long-term survival rates of $>95 \%$ (3). However, some variants of PTC exhibit aggressive behavior and are associated with poor prognosis (4).

The tall cell variant (TCV) of papillary thyroid carcinoma (TCVPTC) was first described by Hawk and Hazard in 1976 (5). TCVPTC is the most common aggressive variant of PTC and it accounts for 4-19\% of all PTCs (6). According to the World Health Organization (WHO) classification, tall cells are modified tumor cells with a height that is 2-3 times greater than their width. These tumor cells have moderate to abundant homogeneous eosinophilic cytoplasm with nuclear features of PTC. At least $30 \%$ of all tumors cells should be TCV for a diagnosis of TCVPTC (7). TCVPTCs present in old age and exhibit more aggressive pathologic features, such as a larger tumor size, increased incidence of extrathyroidal extension (ETE), lymph node metastasis, vascular invasion, and distant metastasis (8-10). Thus, the American Thyroid Association (ATA) management guidelines included the TCV as an independent criterion for categorization of PTC as intermediate-risk rather than low-risk PTC (1).

However, there is no clear consensus with regard to the percentage of tall cells required for the diagnosis of TCVPTC. Interestingly, in some studies, presence of $<30 \%$ tall cells was found to significantly influence the prognosis (11-14). Several studies have sought to investigate the optimal cutoff percentage of tall cells for the diagnosis of TCVPTC $(4,8,15)$. A diagnosis of classic PTC with tall cell features (TCF) was based on classic PTCs having fewer tall cells than the required cutoff percentage. The prognostic significance of classic PTC with TCF is not clear. Owing to the lack of evidence to support the clinical relevance of classic PTC with TCF, we compared the outcomes and tumor characteristics of classic PTCs with TCF and TCVPTC in our series of PTCs.

The purpose of this retrospective study was to investigate the potential differences between TCVPTC and classic PTC with TCF with respect to clinicopathological characteristics and oncologic outcomes in terms of diseasefree survival (DFS).

We present the following article in accordance with STROBE reporting checklist (available at https:// gs.amegroups.com/article/view/10.21037/gs-21-678/rc).

\section{Methods}

\section{Patients}

We performed a retrospective analysis of 526 patients with TCVPTC or classic PTC with TCF who underwent thyroid surgery between January 2013 and December 2018 at the Seoul St. Mary's Hospital (Seoul, Korea). Of these, 11 patients with incomplete data and six patients who were lost to follow-up were excluded from analysis. A total of 509 patients were included in the study. Comprehensive review of medical charts and pathologic reports was performed for all patients. The mean duration of follow-up was $70.7 \pm$ 21.7 months (range, 31-102 months). The study was conducted in accordance with the Declaration of Helsinki (as revised in 2013) and was approved by the institutional review board of Seoul St. Mary's Hospital, The Catholic University of Korea (IRB No. KC21RISI0659). The requirement for informed consent of patients was waived off due to the retrospective nature of the study.

\section{Preoperative work-up}

All patients underwent physical examination, serum thyroid function tests, neck ultrasonography (US), and computed tomography (CT) scan for the preoperative workup. Thyroid nodules were diagnosed based on the findings of preoperative US-guided fine needle aspiration (FNA) cytology using the Bethesda system. All patients diagnosed with PTC were evaluated via preoperative US and neck CT scan to validate the location of tumors and size, presence/ absence of ETE and LN metastasis, and other abnormal findings in the neck. If palpable LNs or suspicious LNs were found on preoperative US or neck CT, FNA and washout thyroglobulin ( $\mathrm{Tg}$ ) evaluation were performed. All FNA procedures were performed under US guidance by experienced radiologists.

\section{Histopathologic review}

All surgical specimens were examined by surgical pathologists who had experience in thyroid disease to identify clinicopathological characteristics and to determine the percentage of tall cells in PTCs. Tall cells were defined as cells whose height was two or more times greater than their width and which had an eosinophilic cytoplasm and characteristic nuclear features of PTC. We used a digital training set with known percentages calculated from digitization of whole slide imaging to determine whether 


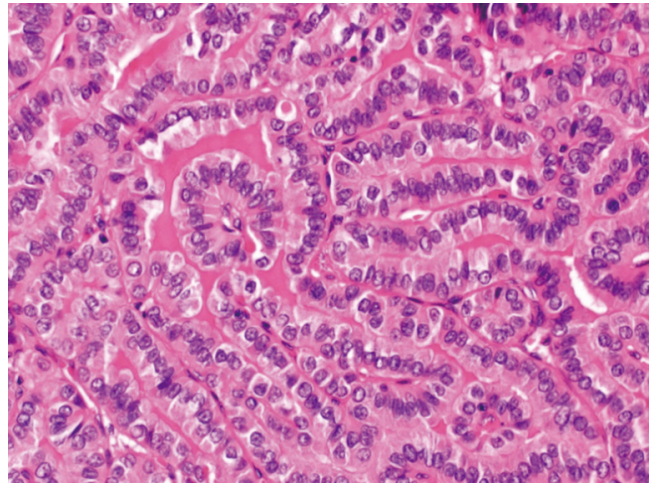

Figure 1 Tall cell variant of PTC exhibits elongated follicular and closely packed papillary growth patterns. Tall cells display prominent cell membranes, dense eosinophilic cytoplasm, and nuclear features typical of PTC $(\mathrm{HE}, \times 400)$. PTC, papillary thyroid carcinoma.

samples reached the cutoff values of $10 \%$ and $30 \%$ of tall cells in the whole sections of tumor tissue.

\section{PTC variant definition}

The PTCs were defined as follows: the criteria for TCVPTC or classic PTC with TCF was based on the WHO classification of tumors of endocrine organs (7).

\section{TCVPTC}

PTC was classified as TCV if it contained at least 30\% tall cells in the entire tumor volume without tumor necrosis or significant mitotic activity ( $>3$ mitoses $/ 10$ high-power fields, $\times 400)$ (Figure 1).

\section{Classic PTC with TCF}

PTC was defined as TCF if it harbored between $10 \%$ and $30 \%$ tall cells (Figure 2). If the tumor was associated with tumor necrosis or significant mitotic activity, it was not considered as classic PTC with TCF.

\section{Postoperative management and follow-up}

Postoperative care and follow-up was conducted according to the ATA management guidelines (1). Patients were administered suppressive doses of levothyroxine for suppression of thyroid stimulating hormone immediately after operation and were regularly followed-up. All patients underwent physical examination, thyroid function tests, serum $\mathrm{Tg}$ concentration, anti-Tg antibody, and neck US every 3-6 months for the first year, and annually thereafter. Postoperative radioactive iodine (RAI) ablation was performed at 6-8 weeks after surgery, and whole-body scans were performed at $5-7$ days after RAI ablation in patients who underwent total thyroidectomy (TT). Patients who showed signs of recurrence on routine follow-up evaluation were assessed via additional diagnostic imaging, including CT scan, positron emission tomography/CT scan, and/ or radioactive iodine whole-body scan, to determine the location and extent of suspected recurrence. In cases of suspected recurrence, diagnosis was confirmed via histologic examination using FNA or a surgical biopsy specimen.

\section{Statistical analysis}

Continuous variables were reported as mean \pm standard deviation and between-group differences assessed using Student's $t$-test. Categorical variables were reported as frequency (percentage) and between-group differences assessed using Pearson's chi-square test or the Fisher's exact test. Univariate and multivariate Cox regression analyses were performed to identify the predictors of DFS using hazard ratios (HRs) with $95 \%$ confidence intervals (CIs). Kaplan-Meier survival analysis was used to estimate DFS and between-group differences in DFS were assessed using the log-rank test. Linear logistic regression analysis was performed to calculate the odds ratios (ORs) with 95\% CI for clinicopathological factors that showed an independent association with worse outcomes. $\mathrm{P}$ values $<0.05$ were considered indicative of statistical significance. All statistical analyses were performed using the Statistical Package for the Social Sciences software for Windows version 23.0 (IBM Corp., Armonk, NY, USA).

\section{Results}

\section{Baseline clinicopathological characteristics}

Table 1 shows the baseline clinicopathologic characteristics of 509 patients with TVCPTC [N=158 (31\%)] or classic PTC with TCF $[\mathrm{N}=351(69 \%)]$. The mean age of patients was 47.2 year, and 384 (75.4\%) patients were female. There were 231 (45.4\%) patients who underwent lobectomy, while the remaining $278(54.6 \%)$ underwent TT. The mean tumor size in our cohort was $1.2 \mathrm{~cm}$. Multifocality and bilaterality of cancer were observed in $178(35.0 \%)$ and 94 (18.5\%) patients, respectively. A total of 64 (12.6\%) patients were pathologically diagnosed as having ETE, 

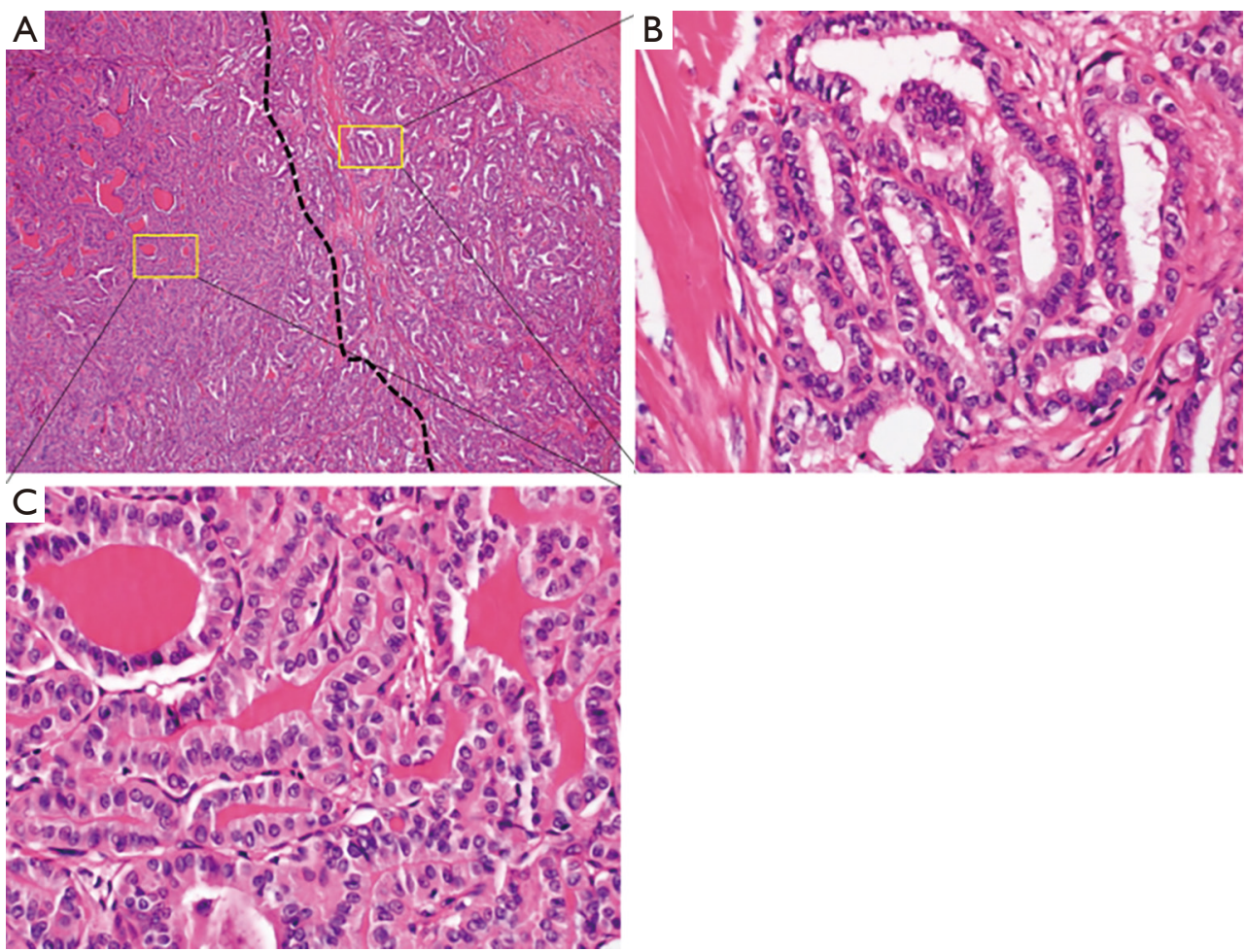

Figure 2 Classic PTC with tall cell features contains $10 \%$ to $30 \%$ of tall cells. (C) Left side from dotted lines of figure (A) (HE, $\times 40)$ shows the area containing tall cells $(\mathrm{HE}, \times 400)$. (B) Classic PTC $(\mathrm{HE}, \times 400)$. PTC, papillary thyroid carcinoma.

$60(11.8 \%)$ showed invasion of the strap muscles, and 8 (1.6\%) patients showed invasion of the subcutaneous soft tissue, trachea, nerve, or esophagus. Lymphatic, vascular, and perineural invasion were observed in 243 (47.7\%), 25 (4.9\%), and 21 (4.1\%) patients, respectively. BRAFV600E test was performed in 373 patients, of whom 359 (96.2\%) patients were positive. The mean number of harvested LNs and positive LNs were 17.6 and 4.0, respectively. The distribution of patients according to each $\mathrm{T}$ stage was as follows: stage 1, 409 (80.4\%) patients; stage 2, 32 (6.3\%) patients; stage 3a, $4(0.8 \%)$ patients; stage 3b, 60 (11.8\%) patients; and stage 4, $4(0.8 \%)$ patients. The number of patients diagnosed with N1a and N1b was 272 (53.4\%) and $70(13.8 \%)$, respectively. The numbers of patients in each TNM stage were as follows: $407(80.0 \%)$ in stage I, $100(19.6 \%)$ in stage II, and $2(0.4 \%)$ stage III. Overall, $229(45.0 \%)$ patients received postoperative RAI ablation. Twenty (3.9\%) patients developed recurrence after the initial treatment.

\section{Comparison of clinicopathological characteristics between TCVPTC and classic PTC with TCF}

The baseline clinicopathological characteristics of TCVPTC and classic PTC with TCF are summarized in Table 2. The extent of surgery in the TCVPTC group was significantly more extensive than that in the classic PTC with TCF group $(\mathrm{P}=0.001$ and $\mathrm{P}=0.032)$. The mean tumor size was significantly larger in the TCVPTC group $(1.3 \pm 0.9$ vs. $1.1 \pm 0.7 \mathrm{~cm}, \mathrm{P}=0.010)$. ETE was significantly more frequent in the TCVPTC group compared with the classic PTC with TCF group $(\mathrm{P}=0.002)$. The proportion of harvested and positive LNs was higher in TCVPTCs $(\mathrm{P}=0.010$ and $\mathrm{P}=0.003$, respectively). TCVPTCs had significantly more advanced $\mathrm{T}$ and $\mathrm{N}$ stage than classic PTCs with TCF ( $\mathrm{P}=0.002$ and $\mathrm{P}=0.019$, respectively). RAI ablation therapy was performed more frequently in the TCVPTC group $(\mathrm{P}=0.001)$. However, there was no significant between-group difference with respect to the recurrence rate $(5.7 \%$ vs. $3.1 \%, \mathrm{P}=0.216)$. Moreover, mean 
Table 1 Baseline clinicopathological characteristics of the study population $(\mathrm{n}=509)$

\begin{tabular}{|c|c|}
\hline Characteristics & Value \\
\hline Age (years) & $47.2 \pm 13.1$ (range, $15-83$ ) \\
\hline Male: female & $1: 3.1$ \\
\hline Male sex & $125(24.6 \%)$ \\
\hline Female sex & $384(75.4 \%)$ \\
\hline \multicolumn{2}{|l|}{ Extent of surgery } \\
\hline Lobectomy & $231(45.4 \%)$ \\
\hline $\mathrm{TT}$ & $278(54.6 \%)$ \\
\hline \multicolumn{2}{|l|}{ Neck dissection } \\
\hline CLND & $439(86.2 \%)$ \\
\hline mRND & $70(13.8 \%)$ \\
\hline \multicolumn{2}{|l|}{ Subtype of PTC } \\
\hline TCVPTC & $158(31.0 \%)$ \\
\hline Classic PTC with TCF & $351(69.0 \%)$ \\
\hline Tumor size $(\mathrm{cm})$ & $1.2 \pm 0.8$ (range, $0.3-5.0$ ) \\
\hline Multifocality & $178(35.0 \%)$ \\
\hline Bilaterality & $94(18.5 \%)$ \\
\hline ETE & $64(12.6 \%)$ \\
\hline Lymphatic invasion & $243(47.7 \%)$ \\
\hline Vascular invasion & $25(4.9 \%)$ \\
\hline Perineural invasion & $21(4.1 \%)$ \\
\hline $\mathrm{BRAF}^{\mathrm{V} 600 \mathrm{E}}$ positivity & $359 / 373(96.2 \%)$ \\
\hline Harvested LNs & $17.6 \pm 21.2$ \\
\hline Positive LNs & $4.0 \pm 6.1$ \\
\hline \multicolumn{2}{|l|}{ T stage } \\
\hline $\mathrm{T} 1 / \mathrm{T} 2 / \mathrm{T} 3 \mathrm{a} / \mathrm{T} 3 \mathrm{~b} / \mathrm{T} 4 \mathrm{a}$ & $\begin{array}{c}409(80.4 \%) / 32(6.3 \%) / 4(0.8 \%) / 60 \\
(11.8 \%) / 4(0.8 \%)\end{array}$ \\
\hline \multicolumn{2}{|l|}{$\mathrm{N}$ stage } \\
\hline N0/N1a/ N1b & $167(32.8 \%) / 272(53.4 \%) / 70(13.8 \%)$ \\
\hline \multicolumn{2}{|l|}{ TNM stage } \\
\hline Stage I/II/III & 407 (80.0\%)/100 (19.6\%)/2 (0.4\%) \\
\hline RAI therapy & $229(45.0 \%)$ \\
\hline Recurrence & $20(3.9 \%)$ \\
\hline Follow-up duration (months) & $70.7 \pm 21.7$ (range, 31-102) \\
\hline
\end{tabular}

Data were expressed as number (\%) or mean \pm standard deviation. TCVPTC, tall cell variant papillary thyroid carcinoma; TCF, tall cell features; TT, total thyroidectomy; CLND, central lymph node dissection; mRND, modified radical neck dissection; ETE, extrathyroidal extension; LN, lymph node; T, tumor; $N$, node; $M$, metastasis; $R A I$, radioactive iodine. age, sex distribution, multifocality, lymphatic invasion, vascular invasion, perineural invasion, BRAFV600E positivity, and TNM stage did not significantly differ between the two groups.

\section{Univariate and multivariate analyses of the risk factors for recurrence}

Table 3 presents the results of univariate and multivariate Cox regression analyses for identifying the risk factors associated with DFS. In univariate analysis, tumor size $>2 \mathrm{~cm}(\mathrm{HR}, 3.372 ; \mathrm{P}=0.013)$, lymphatic invasion (HR, 3.324; $\mathrm{P}=0.020)$, vascular invasion $(\mathrm{HR}, 3.549 ; \mathrm{P}=0.043)$, and positive lymph nodes (HR, 1.070; $\mathrm{P}=0.001)$ showed a significant association with recurrence. Among these, tumor size $>2 \mathrm{~cm}(\mathrm{HR}, 2.671 ; \mathrm{P}=0.048)$ and lymphatic invasion (HR, 2.878; $\mathrm{P}=0.044)$ were identified as significant risk factors for DFS in multivariate analysis. There was no significant difference between the TCVPTC and classic PTC with TCF groups with respect to DFS (log-rank $\mathrm{P}=0.159$; Figure 3).

\section{Linear logistic regression analysis for the risk of clinicopathological factors between TCVPTC and classic PTC with TCF}

Table 4 shows the results of linear logistic regression analysis to identify independent risk factors associated with TCVPTC. Tumor size $>2 \mathrm{~cm}(\mathrm{OR}, 1.922 ; \mathrm{P}=0.019)$, bilaterality $(\mathrm{OR}, 1.668 ; \mathrm{P}=0.030)$, and lateral $\mathrm{LN}$ metastasis $(\mathrm{OR}, 1.700 ; \mathrm{P}=0.045)$ were significantly associated with TCVPTC. Moreover, ETE showed a significant association with TCVPTC compared with classic PTC with TCF (OR, 2.352; $\mathrm{P}=0.002)$.

\section{Discussion}

In this study, we observed similar clinicopathological characteristics and oncological outcomes of patients with TCVPTC and those with classic PTC with TCF. Both these tumors showed aggressive features.

PTC is classified into several variants and some of them are considered aggressive variants, such as diffuse sclerosing, columnar cell, solid, hobnail, and TCV (16-20). TCVPTC is a relatively rare variant, accounting for $4-19 \%$ of all PTCs (6). The criteria for defining TCVPTC is based on the percentage of tall cells and varies between $30 \%$ and $70 \%$ of tumor cells (21). According to the 
Table 2 Baseline clinicopathological characteristics according to histopathologic type

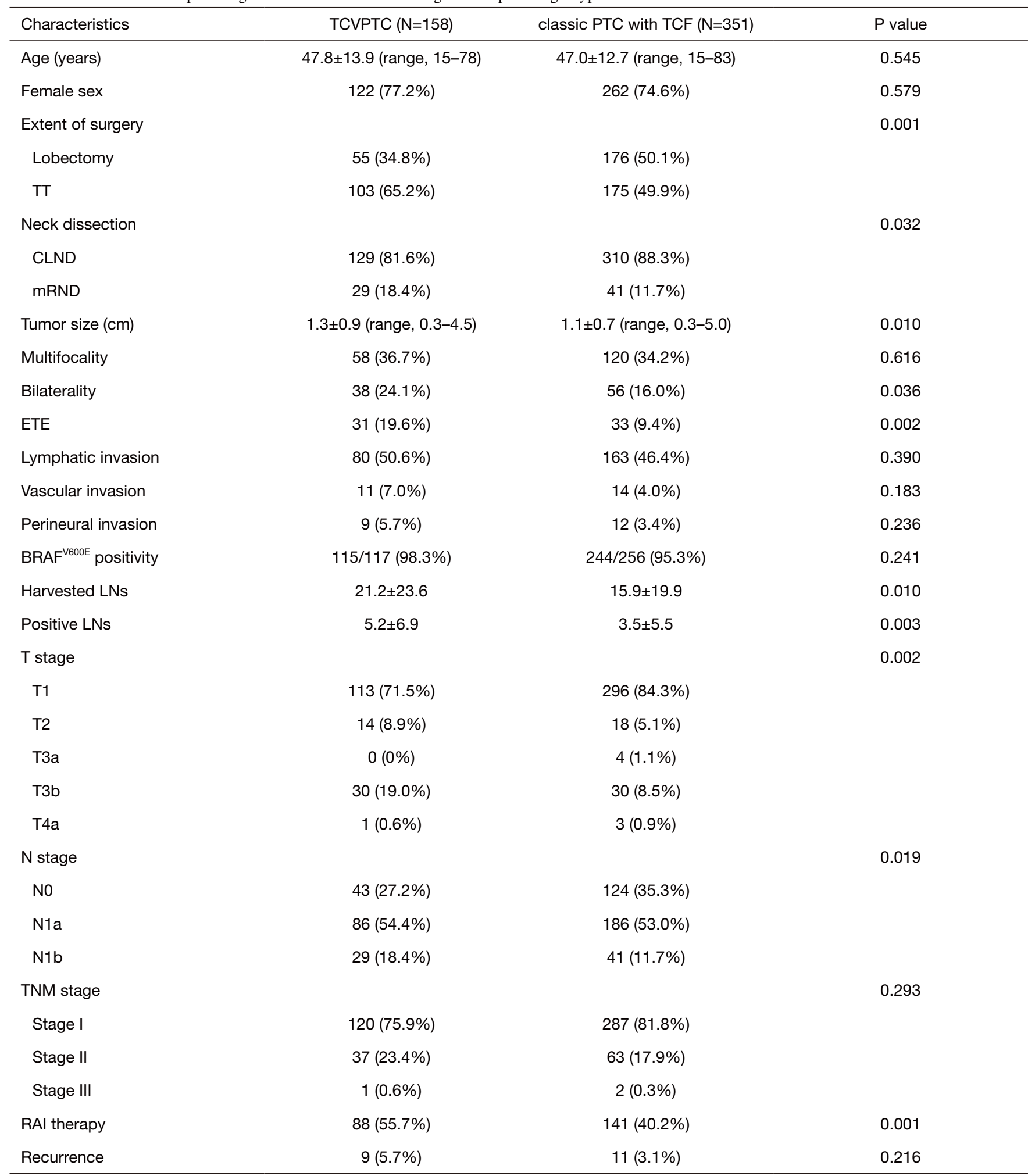

Data were expressed as number (\%) or mean \pm standard deviation. A statistically significant difference was defined as P<0.05. TCVPTC, tall cell variant papillary thyroid carcinoma; TCF, tall cell features; TT, total thyroidectomy; CLND, central lymph node dissection; mRND, modified radical neck dissection; ETE, extrathyroidal extension; LN, lymph node; T, tumor; N, node; M, metastasis; RAI, radioactive iodine. 
Table 3 Univariate and multivariate analyses of DFS

\begin{tabular}{|c|c|c|c|c|}
\hline & \multicolumn{2}{|c|}{ Univariate } & \multicolumn{2}{|c|}{ Multivariate } \\
\hline Tumor size & 1.607 (1.110-2.327) & 0.012 & & \\
\hline$\leq 2 \mathrm{~cm}$ & ref. & & ref. & \\
\hline$>2 \mathrm{~cm}$ & $3.372(1.295-8.780)$ & 0.013 & $2.671(1.009-7.070)$ & 0.048 \\
\hline TCF & ref. & & & \\
\hline TCV & $1.866(0.773-4.503)$ & 0.165 & & \\
\hline Lymphatic invasion & $3.324(1.208-9.147)$ & 0.020 & $2.878(1.028-8.057)$ & 0.044 \\
\hline Vascular invasion & $3.549(1.039-12.115)$ & 0.043 & & \\
\hline
\end{tabular}

A statistically significant difference was defined as $\mathrm{P}<0.05$. DFS, disease-free survival; PTC, papillary thyroid carcinoma; TCF, tall cell features; TCV, tall cell variant; LN, lymph node.

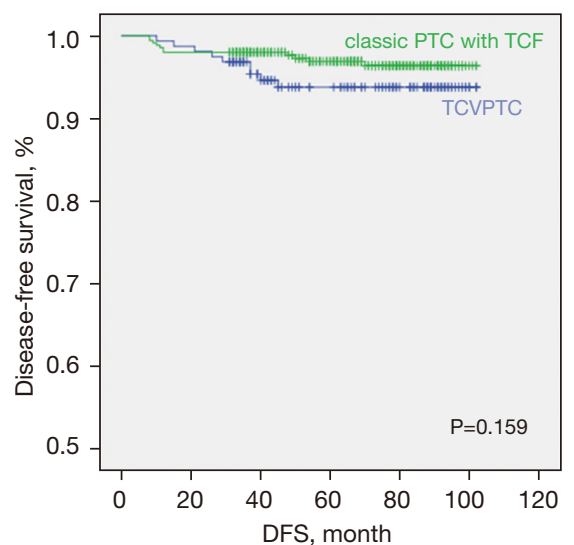

Figure 3 DFS curves according to subtype of PTC (log-rank test, $\mathrm{P}=0.159)$. PTC, papillary thyroid carcinoma; DFS, diseasefree survival; TCF, tall cell features; TCVPTC, tall cell variant of papillary thyroid carcinoma.

ATA management guidelines, TCV is characterized by predominance $(>50 \%)$ of tall columnar tumor cells whose height is at least three times their width (1). However, the most recent $\mathrm{WHO}$ classification $\left(4^{\text {th }}\right.$ edition) adopted the cutoff of $30 \%$ of tall cells in tumor cells (7). Thus, there is no clear consensus on the cutoff percentage of tall cells for defining TCVPTC. The classic PTC with TCF is defined as tumor with noticeable tall cells but less than the percentage required for TCVPTC diagnosis. Some recent studies have found that classic PTC with TCF also exhibits aggressive behavior $(11,22)$. We therefore aimed to compare the clinicopathological features and oncologic outcomes between TCVPTC and classic PTC with TCF.

TCVPTC is typically diagnosed in old age and is characterized by larger tumor size, higher prevalence of ETE, higher stage at presentation, and poorer prognosis compared to classic PTC $(12,15,23,24)$. A meta-analysis by Liu et al. demonstrated that TCVPTC is associated with more aggressive clinicopathological characteristics and poorer prognosis than classic PTC (25). In a study by Kazaure et al., TCVPTC was associated with worse prognosis than classic PTC despite relatively more radical treatment (26). For these reasons, TCVPTC is included in the intermediate-risk category in the 2015 ATA risk stratification system (1). However, the clinicopathological characteristics and prognosis of classic PTC with TCF are not well characterized. In the present study, compared with classic PTC with TCF, TCVPTC had significantly larger tumor size, higher prevalence of ETE and bilaterality, greater proportion of positive LNs, and more advanced $\mathrm{T}$ and $\mathrm{N}$ stage. On linear logistic regression analysis, ETE, larger tumor size, bilaterality, and lateral LN metastasis were significantly associated with TCVPTC compared with classic PTC with TCF. This result is consistent with previous studies in which TCVPTC was found more likely to present with more aggressive pathologic features than classic PTC with TCF. Beninato et al. reported that TCVPTC had more aggressive characteristics than classic PTC with TCF (11). Similarly, in the study by Bongers et al., patients with TCVPTC had more aggressive 
Table 4 Linear logistic regression analyses of TCVPTC $v$ s. classic PTC with TCF

\begin{tabular}{lccc}
\hline Dependent variable & Independent variables & OR $(95 \% \mathrm{Cl})$ & P value \\
\hline ETE & & $2.352(1.382-4.003)$ & 0.002 \\
Tumor size $>2 \mathrm{~cm}$ & Classic PTC with TCV vs. TCVPTC & $1.922(1.115-3.313)$ & 0.019 \\
Bilaterality & $1.668(1.050-2.651)$ & 0.030 \\
Lateral LN metastasis & $1.700(1.013-2.853)$ & 0.045 \\
\hline
\end{tabular}

A statistically significant difference was defined as $\mathrm{P}<0.05$. TCVPTC, tall cell variant papillary thyroid carcinoma; TCF, tall cell features; ETE, extrathyroidal extension; LN, lymph node.

tumor features such as older age at presentation, higher prevalence of ETE, and more LN and distant metastasis (27). Nevertheless, in the present study, recurrence rate was comparable in the two groups.

The aggressive clinicopathological features of classic PTC with TCF translated into poor outcomes with the DFS similar to that in the TCVPTC group. The recurrence rate of classic PTC with TCF was relatively lower compared with TCVPTC ( $3.1 \%$ vs. $5.7 \%, \mathrm{P}=0.216)$. There was no significant between-group difference with respect to DFS $(\mathrm{P}=0.159)$. Moreover, in multivariate analysis, TCVPTC was not an independent predictor of higher rate of recurrence than classic PTC with TCF. Bongers et al. reported that PTC with $<10 \%$ tall cells had a recurrence rate of $3 \%$, but, in contrast, classic PTC with TCF had a $30 \%$ chance of recurrence or persistence. They suggested a possible benefit of more aggressive management, including more extensive surgery and postoperative RAI ablation therapy (27). Beninato et al. reported only $2 \%$ recurrence in classic PTC as against $10 \%$ recurrence in classic PTC with TCF (11). Although classic PTC with TCF is as aggressive as TCVPTC, the ATA management guidelines recommend similar treatment for classic PTC with TCF and classic PTC.

Several studies have suggested various thresholds of the proportion of tall cells (ranging from $30 \%$ to $75 \%$ ) for defining TCVPTC $(9,11,28)$. We used a $10 \%$ threshold for defining classic PTC with TCF and a 30\% threshold for defining TCVPTC according to the 4th edition of the WHO classification. Using this threshold, DFS was not significantly different between the two groups. This finding highlight that even classic PTC with TCF may have a poor clinical course similar to that of TCVPTC. This implies that the adverse prognosis of classic PTC with TCF is underestimated compared to TCVPTC. In recent years, there has been a tendency to use lower thresholds for defining TCVPTC. As a result, we recommend that the percentage of tall cells used to define TCVPTC should be re-considered.

BRAFV600E mutation is the most common genetic alteration in PTC (29). BRAFV600E mutation strongly activates the mitogen-activated protein kinase signaling pathway in human cancers; this leads to uncontrolled cell proliferation and transformation and has been shown to correlate with aggressive features in PTC $(30,31)$. Many studies have reported an association of this mutation with known clinicopathological correlates of recurrence and progression of PTC, including old age, ETE, LN metastasis, and advanced tumor stage (29,32-34). BRAF mutations are reported in approximately $50-70 \%$ of Korean patients with thyroid cancer $(35,36)$. The reported prevalence of BRAF mutation in TCVPTCs is as high as $80 \%$ to $100 \%$ (37). In the present study, BRAFV600E mutation was found in $98.3 \%$ of TCVPTC, and in $95.3 \%$ of classic PTC with TCF. In the study by Bernstein et al., BRAFV600E mutation was detected in $92.6 \%$ patients with TCVPTC (38). The high prevalence of BRAFV600E mutations in TCVPTC and classic PTC with TCF may explain the higher aggressiveness.

Some limitations of this study should be acknowledged. First, the retrospective nature of this study may have introduced an element of bias. Second, our cohort was sourced from a single tertiary institution. Thus, our results may have been affected by selection bias, limiting their generalizability. Third, we did not include classic PTC in this study. Several studies have already confirmed that TCVPTC or classic PTC with TCF is more aggressive than classic PTC. Finally, the follow-up period was relatively short ( $70.7 \pm 21.7$ months) for a tumor that typically has an indolent course; this limited the ability to compare longterm surgical outcomes. A multicenter or prospective study may help overcome these limitations.

However, the study also had some advantages. All patients in our cohort were followed-up with standardized laboratory and imaging protocols. To the best of our 
knowledge, only few studies have compared surgical outcomes between TCVPTC and classic PTC with TCF.

\section{Conclusions}

Our results suggest that TCVPTC and classic PTC with TCF have similar clinicopathological characteristics and oncologic outcomes. However, classic PTC with TCF is still not included in the ATA risk stratification system. Therefore, we suggest a potential re-classification of classic PTC with TCF from low-risk to intermediate-risk category.

\section{Acknowledgments}

Funding: This research was supported by Basic Science Research Program through the National Research Foundation of Korea (NRF) funded by the Ministry of Education (NRF-2015R1D1A1A01058798).

\section{Footnote}

Reporting Checklist: The authors have completed the STROBE reporting checklist. Available at https:// gs.amegroups.com/article/view/10.21037/gs-21-678/rc

Data Sharing Statement: Available at https://gs.amegroups. com/article/view/10.21037/gs-21-678/dss

Peer Review File: Available at https://gs.amegroups.com/ article/view/10.21037/gs-21-678/prf

Conflicts of Interest: All authors have completed the ICMJE uniform disclosure form (available at https://gs.amegroups. com/article/view/10.21037/gs-21-678/coif). CKJ serves as an unpaid editorial board member of Gland Surgery. The other authors have no conflicts of interest to declare.

Ethical Statement: The authors are accountable for all aspects of the work in ensuring that questions related to the accuracy or integrity of any part of the work are appropriately investigated and resolved. The study was conducted in accordance with the Declaration of Helsinki (as revised in 2013) and was approved by the institutional review board of Seoul St. Mary's Hospital, The Catholic University of Korea (IRB No. KC21RISI0659). The requirement for informed consent of patients was waived off due to the retrospective nature of the study.
Open Access Statement: This is an Open Access article distributed in accordance with the Creative Commons Attribution-NonCommercial-NoDerivs 4.0 International License (CC BY-NC-ND 4.0), which permits the noncommercial replication and distribution of the article with the strict proviso that no changes or edits are made and the original work is properly cited (including links to both the formal publication through the relevant DOI and the license). See: https://creativecommons.org/licenses/by-nc-nd/4.0/.

\section{References}

1. Haugen BR, Alexander EK, Bible KC, et al. 2015 American Thyroid Association Management Guidelines for Adult Patients with Thyroid Nodules and Differentiated Thyroid Cancer: The American Thyroid Association Guidelines Task Force on Thyroid Nodules and Differentiated Thyroid Cancer.

Thyroid 2016;26:1-133.

2. Davies L, Welch HG. Increasing incidence of thyroid cancer in the United States, 1973-2002. JAMA 2006;295:2164-7.

3. Clark OH, Duh QY, Kebebew E, et al. Textbook of endocrine surgery. Philadelphia: Jaypee Brothers Medical Publishers, 2016.

4. LiVolsi VA. Papillary carcinoma tall cell variant (TCV): a review. Endocr Pathol 2010;21:12-5.

5. Hawk WA, Hazard JB. The many appearances of papillary carcinoma of the thyroid. Cleve Clin Q 1976;43:207-15.

6. Silver CE, Owen RP, Rodrigo JP, et al. Aggressive variants of papillary thyroid carcinoma. Head Neck 2011;33:1052-9.

7. Lloyd RV, Osamura RY, Klöppel G, et al. WHO Classification of Tumours of Endocrine Organs. WHO Classification of Tumours, 4th Edition, Volume 10. Lyon: IARC Press; 2017.

8. Ghossein R, Livolsi VA. Papillary thyroid carcinoma tall cell variant. Thyroid 2008;18:1179-81.

9. Lee SH, Jung CK, Bae JS, et al. Liquid-based cytology improves preoperative diagnostic accuracy of the tall cell variant of papillary thyroid carcinoma. Diagn Cytopathol 2014;42:11-7.

10. Ito $Y$, Hirokawa $M$, Fukushima $M$, et al. Prevalence and prognostic significance of poor differentiation and tall cell variant in papillary carcinoma in Japan. World J Surg 2008;32:1535-43; discussion 1544-5.

11. Beninato T, Scognamiglio T, Kleiman DA, et al. Ten 
percent tall cells confer the aggressive features of the tall cell variant of papillary thyroid carcinoma. Surgery 2013;154:1331-6; discussion 1336.

12. Ganly I, Ibrahimpasic T, Rivera M, et al. Prognostic implications of papillary thyroid carcinoma with tall-cell features. Thyroid 2014;24:662-70.

13. Dettmer MS, Schmitt A, Steinert H, et al. Tall cell papillary thyroid carcinoma: new diagnostic criteria and mutations in BRAF and TERT. Endocr Relat Cancer 2015;22:419-29.

14. Hernandez-Prera JC, Machado RA, Asa SL, et al. Pathologic Reporting of Tall-Cell Variant of Papillary Thyroid Cancer: Have We Reached a Consensus? Thyroid 2017;27:1498-504.

15. Regalbuto C, Malandrino P, Frasca F, et al. The tall cell variant of papillary thyroid carcinoma: clinical and pathological features and outcomes. J Endocrinol Invest 2013;36:249-54.

16. Regalbuto C, Malandrino P, Tumminia A, et al. A diffuse sclerosing variant of papillary thyroid carcinoma: clinical and pathologic features and outcomes of 34 consecutive cases. Thyroid 2011;21:383-9.

17. Wang S, Xiong Y, Zhao Q, et al. Columnar cell papillary thyroid carcinoma prognosis: findings from the SEER database using propensity score matching analysis. Am J Transl Res 2019;11:6262-70.

18. Vuong HG, Odate T, Duong UNP, et al. Prognostic importance of solid variant papillary thyroid carcinoma: A systematic review and meta-analysis. Head Neck 2018;40:1588-97.

19. Donaldson LB, Yan F, Morgan PF, et al. Hobnail variant of papillary thyroid carcinoma: a systematic review and metaanalysis. Endocrine 2021;72:27-39.

20. Vuong HG, Long NP, Anh NH, et al. Papillary thyroid carcinoma with tall cell features is as aggressive as tall cell variant: a meta-analysis. Endocr Connect 2018;7:R286-93.

21. Ghossein RA, Leboeuf R, Patel KN, et al. Tall cell variant of papillary thyroid carcinoma without extrathyroid extension: biologic behavior and clinical implications. Thyroid 2007;17:655-61.

22. Oh WJ, Lee YS, Cho U, et al. Classic papillary thyroid carcinoma with tall cell features and tall cell variant have similar clinicopathologic features. Korean J Pathol 2014;48:201-8.

23. Michels JJ, Jacques M, Henry-Amar M, et al. Prevalence and prognostic significance of tall cell variant of papillary thyroid carcinoma. Hum Pathol 2007;38:212-9.

24. Jalisi S, Ainsworth T, Lavalley M. Prognostic outcomes of tall cell variant papillary thyroid cancer: a meta-analysis. J Thyroid Res 2010;2010:325602.

25. Liu Z, Zeng W, Chen T, et al. A comparison of the clinicopathological features and prognoses of the classical and the tall cell variant of papillary thyroid cancer: a metaanalysis. Oncotarget 2017;8:6222-32.

26. Kazaure HS, Roman SA, Sosa JA. Aggressive variants of papillary thyroid cancer: incidence, characteristics and predictors of survival among 43,738 patients. Ann Surg Oncol 2012;19:1874-80.

27. Bongers PJ, Kluijfhout WP, Verzijl R, et al. Papillary Thyroid Cancers with Focal Tall Cell Change are as Aggressive as Tall Cell Variants and Should Not be Considered as Low-Risk Disease. Ann Surg Oncol 2019;26:2533-9.

28. Min HS, Lee C, Jung KC. Correlation of immunohistochemical markers and BRAF mutation status with histological variants of papillary thyroid carcinoma in the Korean population. J Korean Med Sci 2013;28:534-41.

29. Liu X, Yan K, Lin X, et al. The association between BRAF (V600E) mutation and pathological features in PTC. Eur Arch Otorhinolaryngol 2014;271:3041-52.

30. Xing M, Alzahrani AS, Carson KA, et al. Association between BRAF V600E mutation and mortality in patients with papillary thyroid cancer. JAMA 2013;309:1493-501.

31. Davies H, Bignell GR, Cox C, et al. Mutations of the BRAF gene in human cancer. Nature 2002;417:949-54.

32. Li X, Abdel-Mageed AB, Kandil E. BRAF mutation in papillary thyroid carcinoma. Int J Clin Exp Med 2012;5:310-5.

33. Yan C, Huang M, Li X, et al. Relationship between BRAF V600E and clinical features in papillary thyroid carcinoma. Endocr Connect 2019;8:988-96.

34. Liu C, Chen T, Liu Z. Associations between BRAF(V600E) and prognostic factors and poor outcomes in papillary thyroid carcinoma: a meta-analysis. World J Surg Oncol 2016;14:241.

35. Choi SY, Park H, Kang MK, et al. The relationship between the BRAF(V600E) mutation in papillary thyroid microcarcinoma and clinicopathologic factors. World J Surg Oncol 2013;11:291.

36. Kim TY, Kim WB, Song JY, et al. The BRAF mutation is not associated with poor prognostic factors in Korean patients with conventional papillary thyroid 
microcarcinoma. Clin Endocrinol (Oxf) 2005;63:588-93.

37. Xing M. BRAF mutation in thyroid cancer. Endocr Relat Cancer 2005;12:245-62.

38. Bernstein J, Virk RK, Hui P, et al. Tall cell variant of

Cite this article as: Kim K, Jung CK, Lim DJ, Bae JS, Kim JS. Comparison of the clinicopathological features and oncologic outcomes of the classic papillary thyroid carcinoma with tall cell features and tall cell variant. Gland Surg 2022;11(1):56-66. doi: $10.21037 / \mathrm{gs}-21-678$ papillary thyroid microcarcinoma: clinicopathologic features with BRAF(V600E) mutational analysis. Thyroid 2013;23:1525-31. 